\title{
UM ÍNDICE DE ÁREAS VERDES (IAV) NA CIDADE DE UBERLÂNDIA / MG ${ }^{1}$
}

Fabiane dos Santos Toledo ${ }^{2}$; Kátia Mazzei ${ }^{3}$; Douglas Gomes dos Santos ${ }^{4}$

(recebido em 31.03.2009 e aceito para publicação em 22.09.2009)

\section{RESUMO}

A cidade de Uberlândia está localizado na mesorregião do Triângulo Mineiro e Alto Paranaíba (MG), com área total de 4.115,82 km², $219 \mathrm{~km}^{2}$ de área urbana onde, em 2006, viviam cerca de 585 mil pessoas. Este artigo tem por finalidade estabelecer um índice de área verde por habitante da área urbana a partir dos dados territoriais de praças e parques disponíveis, para que seja possível seguir metas e objetivos de criação de unidades de conservação e espaços livres de construção, visando à qualidade ambiental e a melhoria da qualidade de vida. O Índice de Área Verde (IAV) para 2000 foi de $7,6 \mathrm{~m}^{2} / \mathrm{hab}$, e de $6,6 \mathrm{~m}^{2} /$ hab para 2006, abaixo do recomendado internacionalmente, demonstrando a necessidade da conservação e da preservação em áreas urbanas.

Palavras-Chave: área urbana, espaços livres de construção, indicadores ambientais, parques urbanos, praças.

\footnotetext{
${ }^{1}$ Artigo oriundo de trabalho de Dissertação na linha de pesquisa "Análise, Planejamento e Gestão Ambiental" - PPG-IG-UFU

${ }^{2}$ Geógrafa, IG-UFU - Uberlândia/MG - fabianests@hotmail.com

${ }^{3}$ Geógrafa, Pesquisador Científico Instituto Florestal de São Paulo, Professora Doutora UNIFIEO I UNIBAN - São Paulo/SP - k mazzei@uol.com.br

${ }^{4}$ Geógrafo, Professor Doutor, Instituto de Geografia - UFU - Uberlândia/MG. Avenida João Naves de Ávila, n. 2121, Bloco 1H - Campus Santa Mônica. CEP: 38.408-902. E-mail: douglasantos@ig.ufu.br
} 


\title{
A GREEN AREA INDEX (GAI) IN UBERLANDIA CITY, MG
}

\begin{abstract}
The city of Uberlandia is located in the middle region of Triangulo Mineiro and Alto Paranaiba (MG), with total area of 4,115.82 km², $219 \mathrm{~km}^{2}$ urban area, where in 2006 there were about 585 thousand people. This article aims to establish an index of green area per capita of the urban area from the territorial data of squares and parks available, in order to follow goals and objectives of creating conservation units and open spaces, aiming at the quality environment and improving the quality of life. The Green Area Index (GAI) for 2000 was $7.6 \mathrm{~m}^{2} / \mathrm{hab}$, and $6.6 \mathrm{~m}^{2} / \mathrm{hab}$ for 2006 , below the recommended internationally, demonstrating the need for conservation and preservation in urban areas.
\end{abstract}

Word-Keys: urban area, open spaces, environmental indicators, urban parks, squares

\section{INTRODUÇÃO}

A existência de espaços livres nas cidades é uma necessidade quando também vinculada aos benefícios deles oriundos, o que eleva ainda mais as importância das áreas verdes. Em vários trabalhos de renomados pesquisadores tem-se discutido o valor dessas áreas para a qualidade de vida da população.

Atualmente, as áreas verdes são essenciais a qualquer planejamento urbano aliado à análise da distribuição espacial da população atual e futura (estimativa). Há também que se pensar nos locais reservados a essas áreas, pois a política de um sistema de áreas verdes não deve se limitar às grandes reservas na periferia da cidade. Citada por Barbin (2003) a carta de Atenas (1969), documento elaborado no IV Congresso Internacional de Arquitetura Moderna, já alertava para esse problema, em que a falta de superfícies livres no interior das cidades faz com que as áreas verdes se situem na periferia, perdendo muitas vezes o caráter de prolongamento direto ou indireto da habitação.

Conforme a cidade cresce, surge a necessidade da manutenção ou criação das áreas verdes. O propósito dessas áreas está relacionado à quantidade, qualidade e a distribuição da mesma dentro da área urbana. Nesse sentido, fica a recomendação para o artigo de Toledo e Santos (2008), contendo a fundamentação teórica para a concepção dos espaços livres de construção.

O índice de áreas verdes é determinado pela quantidade de espaços livres de uso público por habitante da cidade. Pode-se falar em muitos índices ou em muitos elementos fundamentais a serem considerados para esse cálculo. A ideia de que a Organização Mundial de Saúde (OMS) e a Organização das Nações Unidas (ONU) 
recomendariam $12 \mathrm{~m}^{2}$ de área verde por habitante como ideal foi bastante difundida, porém tais organizações não reconhecem esse índice, nem possuem estudos nesse sentido, conforme discutido por Cavalheiro e Del Picchia (1992) que, embasados em consultas e pesquisas, também não adotam nem declaram a existência desta sugestão, seguindo autores que propõem outros índices.

As pesquisas relacionadas ao índice ideal denotam a existência de diversas metodologias, mas não existe um padrão único convencionado. O planejamento de áreas verdes requer, primordialmente, o conhecimento sobre a sua quantidade e a distribuição na malha urbana, bem como a associação desses espaços com a população para, posteriormente, embasados em outros fatores, se fazer o diagnóstico da qualidade de vida dos habitantes, o que torna propensa a avaliação da questão ambiental. É importante ressaltar a evidência de que tal análise é apenas uma das primeiras a se considerar para efetuar uma conclusão efetiva da qualidade de vida da população relacionada às áreas verdes.

Diante das considerações apontadas, torna-se urgente a realização de pesquisas que envolvam os espaços livres nas cidades em crescimento, mais precisamente as áreas verdes como os parques e as praças, para que seja possível um planejamento preventivo de caráter ambiental ou, se for o caso, reverter quadros corrigindo possíveis equívocos.

Uberlândia se enquadra nessas circunstâncias, já que está em fase de expansão e crescimento populacional acelerado. O município possui um importante centro urbano regional, no âmbito do Triângulo Mineiro, com população de 501.214 (IBGE, 2000), e estimada em 600.368 com data de referência em $1^{\circ}$ de julho de 2006 também pelo IBGE.

Como em várias cidades médias brasileiras, Uberlândia tem um número pequeno de pesquisas que analisem tal problemática e discutam o papel das áreas verdes nos centros urbanos, pois como já foi relatado por alguns autores, a cidade já convive com a carência de arborização e espaços livres, sejam parques, praças e canteiros ajardinados, áreas de conservação de mananciais e de cerrado típico.

O aprofundamento de tal questão é de extrema importância, tanto para a população como para os órgãos públicos, pois a política de espaços verdes urbanos é responsabilidade do município e deve ser estabelecida pelo Plano Diretor e Leis de uso do solo, como preconizado nos artigos 4 e 22 da Lei 6.766/79, Lei do Parcelamento do Solo, e também nos artigos 122 (Desenvolvimento e Política Urbanos), 176 (Desporto e Lazer) e 202 (Proteção ao Meio Ambiente) da Lei Orgânica do Município de Uberlândia.

Este artigo tem a perspectiva de quantificar as áreas verdes do perímetro urbano de Uberlândia consideradas de maior relevância, como os parques e as praças, para os 
anos de 2000 e 2006, além de analisar a relação entre a proporção dessas áreas com a população no Município, com os objetivos principais de verificar a real existência do Índice de Áreas Verdes proposto na Lei Orgânica, além de fornecer subsídios ao planejamento urbanístico e ambiental, propondo alternativas para tais estratégias.

\section{Legislação e Áreas Verdes}

É preciso indicar, primeiramente, os preceitos da Constituição Federal para o patrimônio histórico e paisagístico, no qual, em seu Art. 24 esclarece que compete à União, aos Estados e Distrito Federal legislar corretamente sobre sobre a proteção do patrimônio (histórico, cultural, artístico, turístico e paisagístico), assim como é responsável por danos "ao ambiente, ao consumidor, a bens e direitos de valor artístico, estético, histórico, turístico e paisagístico".

Os Sistemas de Áreas Verdes, em geral, são estruturados com base no Plano Diretor de Desenvolvimento Urbano, que é o instrumento básico de definição do modelo de desenvolvimento para municípios com mais de vinte mil habitantes, como preconizado no Estatuto da Cidade (Lei 10.257/2001). Atualmente, este documento está incorporando o enfoque ambiental passando a se chamar Plano Diretor de Desenvolvimento Urbano e Ambiental (PDDUA), ou então Plano Diretor de Desenvolvimento Integrado (PDDI).

A Lei $n^{\circ} 6.766$ de 19 de dezembro de 1979, regulamentou o parcelamento do solo urbano, em seu artigo 4 , inciso 1, parágrafo 10, preconizando que os loteamentos deviam possuir áreas destinadas a espaços livres de usos públicos, proporcionais à densidade de ocupação prevista para a gleba, não podendo ser inferiores a 35\% (trinta e cinco por cento) da gleba, exceto nos loteamentos maiores que $15.000 \mathrm{~m}^{2}$ (quinze mil metros quadrados), caso em que a porcentagem poderia ser reduzida.

Porém, este dispositivo legal foi atualizado e alterado pela Lei $n^{\circ} 9.785$ de 29 de janeiro de 1999, na qual a porcentagem destes espaços não é mais quantificada e deve ser prevista pelo Plano Diretor ou aprovada por Lei Municipal para a zona em que se situem, que definirá os usos permitidos e os índices urbanísticos de parcelamento e ocupação do solo, incluindo, obrigatoriamente, as áreas mínimas e máximas de lotes e os coeficientes máximos de aproveitamento.

A Lei Complementar $n^{\circ} 245$ de 30 de novembro de 2000 (Art. 13), dispõe sobre o parcelamento e zoneamento do uso e ocupação do solo do município de Uberlândia, subseção I, do loteamento e reloteamento, destacando que $20 \%$ da área é voltada ao sistema viário, $10 \%$ para usos institucionais, e $7 \%$ para áreas de recreação pública. Esta Lei ainda define, no art. 5, "Área de Recreação" como sendo "aquela reservada a 
atividades culturais, cívicas, esportivas e contemplativas da população, tais como praças, bosques e parques."

O Plano Diretor de Uberlândia, Lei Complementar $n^{\circ}$ 432, de 19 de outubro de 2006, tem como diretriz ambiental, no art. 14, alínea III, "garantir a proteção dos recursos hídricos e vegetais, a redução dos problemas de drenagem e a criação de áreas para lazer na concepção dos parques, áreas de preservação e unidades de conservação".

Com relação ao que se dispõe ao lazer a Lei Orgânica do Município, o Art. 176 estabelece que o município proporcione meios de recreação sadia e construtiva à comunidade, mediante "reserva de espaços verdes ou livres, em forma de parques, bosques, jardins e assemelhados, como base física da recreação urbana". No Art. 202, alínea XXIII, a Lei propõe: "estimular e contribuir para a recuperação da vegetação em áreas urbanas, com plantio de árvores preferencialmente frutíferas objetivando, especialmente, atingir os índices mínimos de área verde por habitante estipulados pela ONU."

Para o Estado, Decreto n²1.724, de 23 de novembro de 1981 que regulamenta os Parques Estaduais, "Art. $2^{\circ}$ - Os Parques Estaduais são bens do Estado de Minas Gerais, criados para a proteção e preservação permanente de regiões dotadas de excepcionais atributos da natureza, ou de valor científico ou histórico, postos à disposição do povo".

A PMU define área verde como "toda área onde predominar qualquer forma de vegetação, quer seja nativa ou não, de domínio público ou privado", conforme se aplica no art. $164^{\circ}$ da Lei Complementar $n^{\circ}$ 017, mas para as categorias ainda não há um Regulamento específico que defina essas áreas. O que se menciona sobre parques, ainda que Parques Florestais, é que eles são "unidade de conservação permanente destinada a resguardar atributos de natureza, conciliando a proteção integral da flora, da fauna e das belezas naturais com a utilização para objetivos educacionais, recreativos e científicos".

A possível definição de praças é citada em um documento legal apenas para efeito do Decreto $n^{0} 7.383$ de 04 de setembro de 1997, o qual regulamenta o projeto "adote uma praça ou um canteiro central" como "logradouro público situado em vias públicas, com finalidade de instalação de equipamentos de lazer, recreativos e com caráter ornamental, contemplativo e de melhoria da qualidade de vida". 


\section{MATERIAIS E MÉTODOS}

\section{Índice de Áreas Verdes}

Indicadores e índices são números que procuram descrever um determinado aspecto da realidade, ou apresentam uma relação entre vários deles (MAGALHÃES JR, 2007). Adotando-se técnicas para determinação dos valores, podem ser criados índices que sintetizem um conjunto de aspectos da realidade e que representem conceitos mais complexos como a qualidade de vida. Dentre alguns indicadores que expressam a qualidade ambiental de uma cidade destaca-se: o Índice de Áreas Verdes (IAV) que mede a relação entre a quantidade de área verde $\left(\mathrm{m}^{2}\right)$ e a população que vive em determinada cidade.

Os IAV são expostos de diferentes formas por diferentes pesquisadores para diferentes cidades sendo, talvez, uma consequência da falta de consenso entre os conceitos e procedimentos adotados pelos municípios. Cavalheiro e Nucci (1998) alertam que o confronto de índices de áreas verdes entre cidades pode ser um equívoco, pois o índice desacompanhado da definição de termo "área verde" não estabelece parâmetros para comparações. Além disso, sabe-se que muitas administrações aumentam seus índices colocando todo espaço não construído como área verde e/ou até consideram a projeção das copas das árvores sobre as calçadas.

No entanto, em termos gerais, o IAV é aquele que denota a quantidade de espaços livres de uso público, em $\mathrm{km}^{2}$ (quilômetro quadrado) ou $\mathrm{m}^{2}$ (metro quadrado) dividido pela quantidade de habitantes de uma cidade. Assim, entende-se por índice de área verde por habitante a relação matemática existente entre o número de habitantes e o total em metros quadrados de áreas verdes, de uma cidade ou de partes dela.

É importante ressaltar que, para Guzzo (2003) apud Rondino (2005), essa matemática é feita entre os espaços nos quais o acesso da população é livre, ou seja, as praças, os parques e os cemitérios. Para aquele autor, o índice deveria, primeiramente, ser calculado em função da quantidade total das áreas existentes e, posteriormente, recalculado, demonstrando quantas dessas áreas estão sendo realmente utilizadas, após uma avaliação do seu estado de uso e conservação. Todavia, este índice está intimamente ligado à função de lazer que esses espaços desempenham ou que venham a desempenhar.

Nucci (2001) afirma que, para calcular o índice de área verde, devem ser consideradas somente as áreas verdes públicas localizadas na zona urbana e ligadas ao uso direto da população residente nessa área.

Cavalheiro e Del Picchia (1992) referem-se ao índice mais difundido no Brasil, o qual teria sido sugerido pela OMS, pela ONU e pela Organização das Nações Unidas 
para a Alimentação e a Agricultura (FAO), que considerariam como ideal para cada cidade o índice de $12 \mathrm{~m}^{2}$ de área verde/habitante. Porém, os autores mencionados e a ONU não admitem esses estudos nem reconhecem tal sugestão. A Sociedade Brasileira de Arborização Urbana (SBAU) propôs como índice mínimo para áreas verdes públicas destinadas à recreação o valor de 15 m²/habitante (SBAU, 1996). Para Escada (1987), os índices são instrumentos que devem ser utilizados como guia para questões muito complexas e por isso são muito subjetivos.

Oliveira (1996) fez um levantamento das áreas públicas do município de São Carlos (SP) e obteve dois índices diferentes: o primeiro, chamado percentual de áreas verdes (PVA), foi estimado para grandes áreas da cidade, no qual entraram todas as áreas verdes públicas da cidade, sem contar a acessibilidade da população. Posteriormente, foi calculado o índice de áreas verdes (IAV), considerando somente as áreas verdes públicas de acesso livre para a população. O índice de áreas verdes para a cidade como um todo também foi calculado e considerado um indicador de qualidade de vida da população.

Para a cidade de Juiz de Fora (MG), com população equivalente à de Uberlândia, Costa e Ferreira (2009) observaram um índice abaixo de $2,5 \mathrm{~m}^{2} /$ habitante. A PMU através do artigo 202 da Lei Orgânica do Município, atualizada até 08/02/2006, assegura os índices de área verde por habitante para a cidade, embasados nos possíveis valores propostos pela ONU, de $12 \mathrm{~m}^{2}$ per capita.

Com o surgimento espontâneo e o crescimento rápido e desordenado das cidades, a vegetação natural foi, aos poucos, sendo substituída por elementos da infraestrutura urbana constituídos basicamente por concreto, cerâmica, metais, vidro e asfalto. As cidades, ao terem seus componentes urbanos construídos com esses materiais, têm como resultante as superfícies com elevado índice de reflexão, bem como a impermeabilidade quase total dos solos, segundo Barbin (2003).

A alta concentração da população gera a deterioração da qualidade de vida urbana acarretando em desconforto por meio da deficiência no abastecimento em geral, problemas na eliminação e deposição de lixo, ruídos, poluição, congestionamentos, competição, escassez de espaços livres para o lazer e falta de participação popular. Sendo este um problema que atinge a maioria das cidades de médio a grande porte, questiona-se um número que expresse a densidade populacional ideal, o que de acordo com as pesquisas bibliográficas seria entre 100 e 500 habitantes/ha. 


\section{Localização da Área de Estudo}

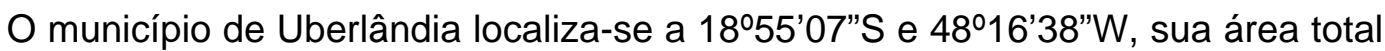
é de $4.115,82 \mathrm{~km}^{2}\left(219,00 \mathrm{~km}^{2}\right.$ de área urbana e $3.896,82 \mathrm{~km}^{2}$ de zona rural), conforme Brito e Prudente (2005). Está situado na Mesorregião do Triângulo Mineiro/Alto Paranaíba, Estado de Minas Gerais, Região Sudeste do Brasil. É dividido em 05 Distritos (Uberlândia - Distrito Sede; Cruzeiro dos Peixotos, Martinésia, Miraporanga, e Tapuirama).

\section{Áreas Verdes no Município de Uberlândia}

De acordo com o memorial descritivo da SEPLAMA, das pesquisas em documentos no Núcleo de Coordenação das Unidades de Conservação (UCs) e da análise dos decretos de criação dos espaços livres em Uberlândia, categorizando parques e praças, foi possível constatar as características descritas a seguir.

\section{Parques}

Em termos de classificação foi verificado que o município não tem nenhum documento legal ou mesmo concordância entre as secretarias responsáveis pelo meio ambiente e patrimônio no que se refere ao conceito de Parque Municipal. Assim fica estabelecido para este estudo, as Leis Federais e Estaduais existentes como a Lei 4.771, de 15 de setembro de 1965, o Código Florestal, que permite a criação dos parques nos termos do artigo 5, alínea "a", a qual foi revogada pelo SNUC.

Todos os Decretos de criação determinam a finalidade dos Parques conforme o mesmo artigo 5, alínea "a" do Código Florestal, ou seja, "de resguardar atributos excepcionais da natureza, conciliando a proteção integral da flora, da fauna e das belezas naturais com a utilização para objetivos educacionais, recreativos e científicos"; e ainda acrescentam a responsabilidade sob as condições do bem estar público. Para ressaltar, os Parques Municipais Santa Luzia, Victório Siquierolli e Natural do Óleo são UCs, no grupo de Unidades de Proteção Integral, que de acordo com o art. 2, alínea VI do SNUC entende-se por "manutenção dos ecossistemas livres de alterações causadas por interferência humana, admitido apenas o uso indireto dos seus atributos naturais;"

Assim, o município de Uberlândia possui sete Parques Municipais de acordo com os Decretos $n^{0} 7.452$ de 27 de novembro de 1997, no 8.166 de 05 de maio de 2000 e $n^{\circ} 9.505$ de 02 de junho de 2004. Em relação à área total dos mesmos foi comprovada uma divergência nas informações da SEPLAMA com os Decretos mencionados, conforme resumida nas Tabelas 1 e 2 . A diferença entre os totais resulta em $44.498,83 \mathrm{~m}^{2}$, é de se ressaltar também que ao observar as individualidades são 
constatadas disparidades em todas as áreas, por vezes menores em uma e maiores em outra e vice-versa.

Para este estudo foram consideradas as áreas referentes aos Decretos por se tratarem de medidas com respaldo legal e por contemplarem uma área maior, referindose aqui ao total geral, já que comparando os dados observam-se discrepâncias individuais. Além disso, parte dessas áreas se comprovaram, no BDI, conforme Tabela 3 , a qual também demonstra pequenas distorções nas quantidades.

Tabela 1 - Distribuição de áreas dos Parques Municipais - SEPLAMA

\begin{tabular}{lr}
\hline \multicolumn{1}{c}{ Parque } & \multicolumn{1}{c}{ Área $\mathbf{( m}^{\mathbf{2}} \mathbf{2}$} \\
\hline Santa Luzia & $271.554,05$ \\
Luizote de Freitas & $51.527,24$ \\
Distrito Industrial & $339.696,25$ \\
Mansour & $238.967,19$ \\
Sabiá & $1.611 .270,56$ \\
Victório Siquierolli & $223.936,95$ \\
Natural do Óleo & $202.897,09$ \\
\hline \multicolumn{1}{c}{ Total } & $\mathbf{2 . 9 3 9 . 8 4 9 , 3 3}$ \\
\hline
\end{tabular}

Fonte: SEPLAMA - Divisão de Planejamento Integrado, 2006 (Org.: TOLEDO, F. S. 2006)

Tabela 2 - Distribuição de áreas dos Parques Municipais - DECRETOS

\begin{tabular}{|c|c|}
\hline Parque & Área $\left(\mathrm{m}^{2}\right)$ \\
\hline Santa Luzia & $268.304,34$ \\
\hline Luizote de Freitas & $55.900,00$ \\
\hline Distrito Industrial & $282.400,00$ \\
\hline Mansour & $117.198,48$ \\
\hline Sabiá & $1.840 .747,80$ \\
\hline Victório Siquierolli & $232.311,19$ \\
\hline Natural do Óleo & $187.486,35$ \\
\hline Total & $2.984 .348,16$ \\
\hline
\end{tabular}

Fonte: SEPLAMA - Divisão de Patrimônio, 2006 (Org.: TOLEDO, F. S. 2006)

Tabela 3 - Unidades de Conservação Ambiental - BDI (2006) 


\begin{tabular}{|c|c|}
\hline Caracterização & Área $\left(\mathrm{m}^{2}\right)$ \\
\hline Parque Municipal do Sabiá & $1.850 .000,00$ \\
\hline Parque Municipal Luizote de Freitas & $55.900,00$ \\
\hline Parque Municipal Santa Luzia & $268.304,34$ \\
\hline Parque Municipal Mansour & $117.198,48$ \\
\hline Parque Municipal Distrito Industrial & $282.000,00$ \\
\hline Parque Municipal Victório Siquierolli & $232.311,19$ \\
\hline Parque Municipal do Óleo & $187.000,00$ \\
\hline Parque Municipal São Francisco de Assis & $1.192 .300,00$ \\
\hline Total & $4.185 .014,01$ \\
\hline
\end{tabular}

Fonte: PMU/BDI, 2006

Para os cálculos até 2000 não foi considerada a área do Parque Natural do Óleo, pois sua criação é de 2004. Acerca do Parque Municipal São Francisco de Assis, observado na Tabela 3, firma-se que o mesmo é localizado na zona rural do município, não integrando, portanto, a área estudada.

Apesar de a presente pesquisa ter como foco principal as medidas totais, foi imprescindível o estudo particular de cada parque para constatação de dados estatísticos, geográficos, estruturais e coletas fotográficas. A distribuição dos parques urbanos e das praças no perímetro urbano de Uberlândia está apresentada na Figura 1.

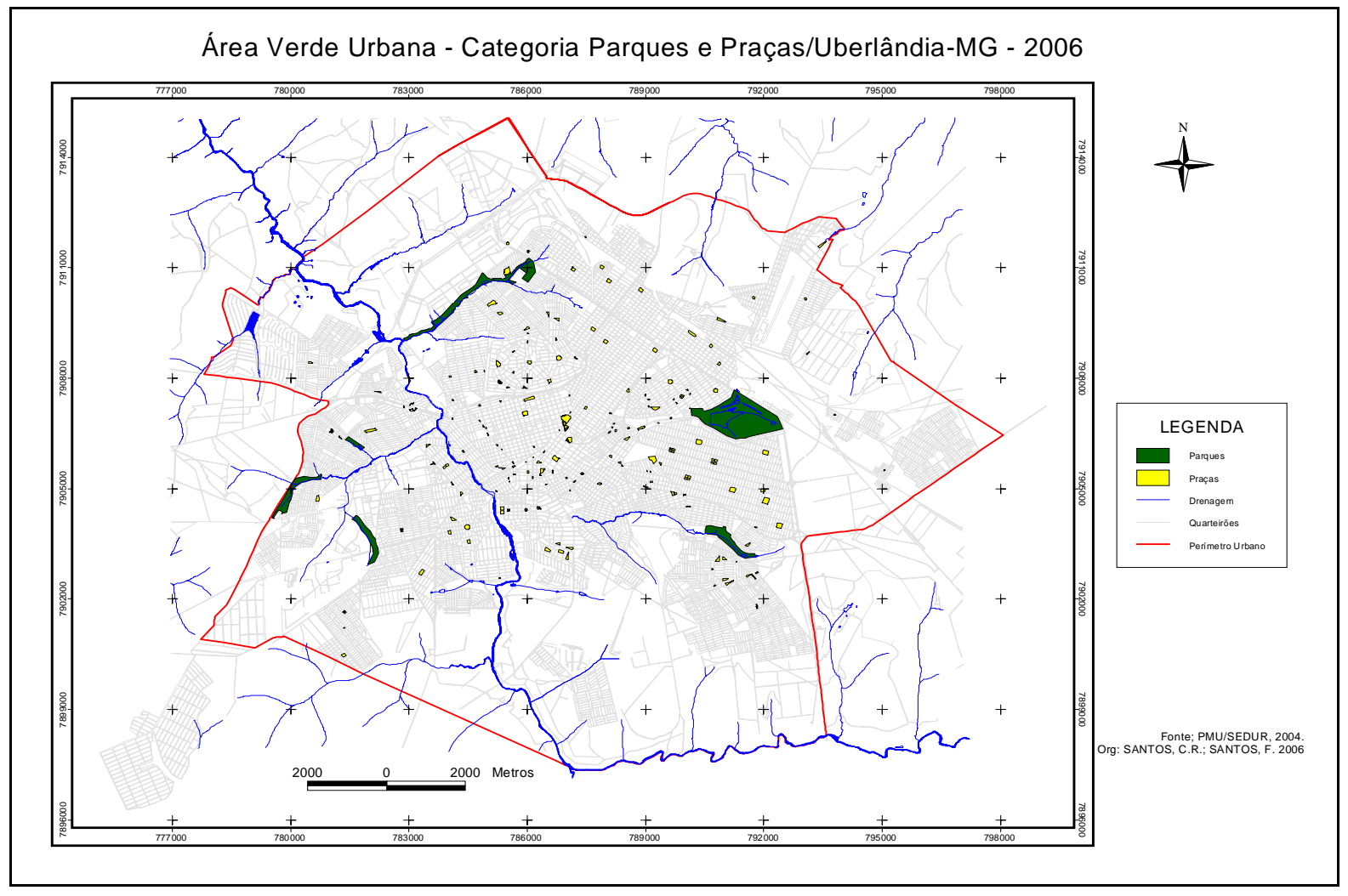

Fonte: Uberlândia, 2007.

Figura 1 - Parques e praças no perímetro urbano de Uberlândia-MG.

\section{Praças}


De acordo com a conferência na lista de praças fornecida pelo Departamento de Serviços Urbanos da PMU, utiliza-se os termos praças urbanizadas, pré-urbanizadas e não urbanizadas. É importante destacar que a PMU considera praças não urbanizadas aquelas que não possuem equipamentos para a recreação e o lazer, apesar de se situarem na área urbana.

Uberlândia possui 189 praças, somando um total de 909.956,83 $\mathrm{m}^{2}$. Destas, 132 são consideradas urbanizadas, ou seja, têm gramado, calçada, bancos, meio-fio, playground e quadra esportiva; 9 são pré-urbanizadas, apresentam arborização e grama; e 48 não são urbanizadas, o que significa que há a disponibilidade da área, mas que ainda se encontram sem infra-estrutura. Isso quer dizer que 57 praças na cidade não são dotadas de mobiliário urbano nem de equipamentos suficientes para a recreação e o lazer e, por isso, não cumprem suas funções de espaço livre de construção, até o momento.

\section{População do Município de Uberlândia}

Realizou-se um levantamento dos dados acerca do crescimento populacional da área, tendo como referência os dados censitários de 2000 e estimativas para 2006, do IBGE e da Secretaria de Desenvolvimento e Planejamento Urbano. Primeiramente foram analisados os dados populacionais segundo estudos do IBGE, do ano de 2000, o qual quantificou 488.982 habitantes na área urbana do Município. A fim de conhecer a densidade populacional de cada setor os dados foram compilados e distribuídos na Tabela 4, de acordo com a subdivisão do perímetro urbano.

\begin{tabular}{|c|c|c|}
\hline Setor & Área $\left(\mathrm{km}^{2}\right)$ & População \\
\hline Central & 13.728 & 87.356 \\
\hline Oeste & 34.309 & 113.511 \\
\hline Leste & 25.234 & 111.186 \\
\hline Norte & 11.662 & 86.682 \\
\hline Sul & 23.503 & 90.247 \\
\hline Total & 108.436 & 488.982 \\
\hline
\end{tabular}

A Tabela 4 pode indicar futuras conclusões no que se refere à população em relação à distribuição de áreas verdes. Posteriormente foi utilizado o mesmo procedimento para a população estimada para 2006 - 600.368 - também segundo o IBGE, sendo tal cálculo para todo o município de Uberlândia, conforme a Tabela 5. 
Tabela 5 - Estimativa populacional - Uberlândia / perímetro urbano (2006)

\begin{tabular}{lcc}
\hline \multicolumn{1}{c}{ Setor } & Área $\left.\mathbf{( k m}^{\mathbf{2}}\right)$ & População \\
\hline Central & 13.728 & 104.623 \\
Oeste & 37.274 & 135.961 \\
Leste & 25.234 & 133.190 \\
Norte & 14.947 & 103.841 \\
Sul & 23.503 & 108.108 \\
\hline Total & $\mathbf{1 1 4 . 6 8 6}$ & $\mathbf{5 8 5 . 7 2 3}$ \\
\hline
\end{tabular}

Foi constatada uma população urbana de 585.723 habitantes para o ano de 2006. Esses dados foram resumidos e finalizados na Tabela 6.

Tabela 6 - População 2000 e Estimativa 2006

\begin{tabular}{lcc}
\hline \multicolumn{1}{c}{ Área } & 2000* & 2006** \\
\hline Urbana & 488.982 & 585.723 \\
Rural & 12.232 & 14.645 \\
\hline Total & $\mathbf{5 0 1 . 2 1 4}$ & $\mathbf{6 0 0 . 3 6 8}$ \\
\hline Fonte: IBGE/SEPLAMA, 2006 (Org.: TOLEDO, F. S. 2006) \\
* Censo/IBGE 2000 ** Cálculos realizados pela estimativa/IBGE 2006
\end{tabular}

Existem várias procedimentos para o estudo das áreas verdes urbanas, assim como há também uma variedade de conceitos para defini-las. Para atingir os objetivos propostos, o método usado foi uma revisão bibliográfica acerca dos conceitos como espaços livres, áreas verdes, índices de áreas verdes, parques, praças e outros que se fizeram necessários, com o aporte dos principais autores no assunto, possibilitado compreender e escolher o embasamento e os indicadores, referenciando a idéia de realizar o levantamento, a quantificação e a análise simplificada das áreas verdes urbanas de Uberlândia, tendo como destaques os parques e as praças.

O material básico foi o índice de espaços verdes de Uberlândia e, para a sua execução, usou-se os aspectos do município proeminentes ao estudo das áreas verdes, por meio de consultas efetivas ao Banco de Dados Integrados de Uberlândia (BDI) 2006, obtido na Secretaria Municipal de Planejamento Urbano e Meio Ambiente (SEPLAMA), os quais possibilitaram a elaboração e organização dos mapas e a construção de tabelas e figuras para a escala de abordagem necessária.

Para a identificação das áreas verdes foram empregados, além da carta base do município, mapas colhidos na Prefeitura Municipal de Uberlândia (PMU) e na Secretaria 
Municipal de Desenvolvimento Urbano (SEDUR), que foram organizados de acordo com a intenção de exibição dos mesmos. A proposta de utilização da cartografia digital como a base principal para representar as áreas verdes do município (parques e praças) encontra respaldo na importante ferramenta que representa na análise urbana.

Como ilustrações dos principais pontos de áreas verdes da área urbana, caso do Parque do Sabiá (representado pelas Figuras 2 e 3), realizou-se diversos trabalhos em campo para o recolhimento de fotografias e informações, utilizando também figuras em diversas escalas, selecionadas no portal eletrônico da PMU. Os dados censitários da área foram recolhidos em dois momentos, primeiro no Instituto Brasileiro de Geografia e Estatística (IBGE), e no outro na SEPLAMA, na Coordenação do Núcleo de Pesquisa Estatística e Banco de Dados do Município de Uberlândia.

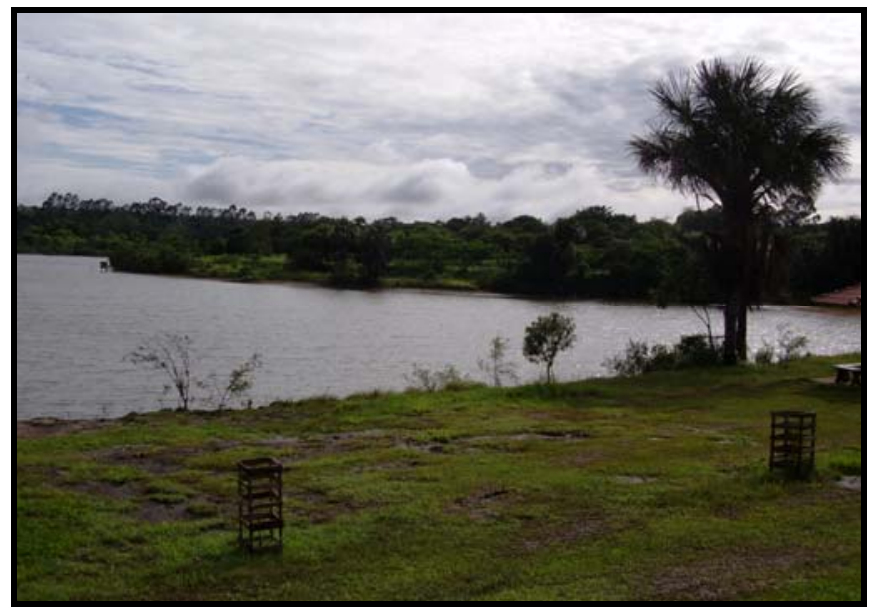

Foto: TOLEDO, F. S., 2006

Figura 2 - Parque do Sabiá

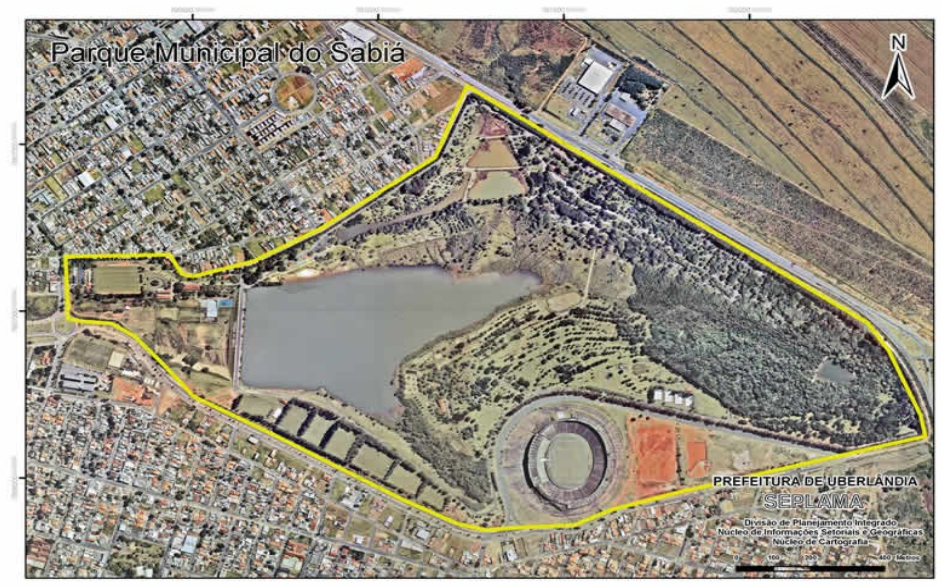

Fonte: Uberlândia, 2007.

Figura 3 - Parque Municipal do Sabiá

Dentre os vários métodos existentes para se computar o Índice de Áreas Verdes (IAV), foi escolhido o mais utilizado para o cálculo, ou seja, a consideração do somatório 
das áreas verdes em metros quadrados $\left(\mathrm{m}^{2}\right)$ dividido pela população da área estudada. Tal procedimento é embasado nas considerações de Nucci (2001) quando afirma que, para calcular o índice de área verde, devem ser consideradas somente as áreas verdes públicas localizadas na zona urbana e ligadas ao uso direto da população residente nessa área.

Para se obter a somatória dessas áreas, foram realizadas visitas e entrevistas na PMU, junto à Secretaria de Planejamento Urbano e recolhidas informações no memorial descritivo da mesma, além de visitas aos próprios locais para confirmação de dados. Após o levantamento das informações necessárias, somou-se a área dos parques e das praças, para a determinação do índice para a área urbana.

Para se obter o IAV neste estudo foi escolhida a metodologia mais utilizada para o cálculo (que não é a única, há de se recordar), a qual considera o somatório total das áreas verdes urbanas (aqui, nas categorias parques e praças), expressa em metro quadrado, dividido pelo número de habitantes da área urbana, conforme a fórmula apresentada no Quadro 1.

Quadro 1 - Fórmula para o cálculo do IAV

TAVC $=\Sigma$ áreas de parques $\left(\mathrm{m}^{2}\right)+\Sigma$ áreas de praças $\left(\mathrm{m}^{2}\right)$

$\mathrm{IAV}=\frac{\mathrm{TAVC}}{\mathrm{NH}}$

Onde:

TAVC = Total de áreas verdes consideradas (parques e praças)

IAV = Índice de área verdes

$\mathrm{NH}=$ Número de habitantes 


\section{RESULTADOS E DISCUSSÕES}

\section{Índice de Área Verde na Cidade de Uberlândia}

No intuito de analisar o índice de áreas verdes foram considerados os períodos relacionados tanto à população quanto à criação dos parques, os cálculos dos índices foram realizados em dois momentos com seus respectivos fatores, ou seja, para o ano de 2000 (Censo IBGE) e 2006 (Estimativa e ano de parte da realização deste estudo). Obtendo os seguintes resultados:

Para 2000,

TAVC $=\Sigma$ áreas de parques $\left(\mathrm{m}^{2}\right)+\Sigma$ áreas de praças $\left(\mathrm{m}^{2}\right)$

TAVC $=2.796 .861,81+909.956,83$

TAVC $=3.706 .818,64$

$$
\begin{aligned}
& I A V=\frac{\text { TAVC }}{\mathrm{NH}} \\
& \mathrm{IAV}=\frac{3.706 .818,64}{488.982,00}
\end{aligned}
$$

IAV = 7,6m² pl hab.

Para 2006,

TAVC $=\Sigma$ áreas de parques $\left(\mathrm{m}^{2}\right)+\Sigma$ áreas de praças $\left(\mathrm{m}^{2}\right)$

TAVC $=2.984 .348,16+909.956,83$

TAVC $=3.894 .304,99$

$$
\mathrm{IAV}=\frac{\mathrm{TAVC}}{\mathrm{NH}}
$$




$$
\mathrm{IAV}=\frac{3.812 \cdot 200,44}{585.723,00}
$$

$I A V=6,6 \mathrm{~m}^{2} \mathrm{p} / \mathrm{hab}$

O índice de áreas verdes, nas categorias praças e parques para a área urbana do município de Uberlândia, no ano de 2006, era de 6,6 $\mathrm{m}^{2} /$ habitante. O que atesta uma falha nos objetivos propostos pela PMU promulgados na Lei Orgânica do Município 001/91 (2006), a qual assegura os índices de área verde por habitante, embasados nos possíveis valores propostos pela ONU, isto é, $12 \mathrm{~m}^{2}$ per capita. Com os cálculos realizados para os períodos censitários, 2000 e 2006, verificou-se que, mesmo com criação de mais um parque, neste caso o Natural do Óleo, o índice diminuiu em torno de $13 \%$, pois o aumento da população não foi acompanhado da criação de parques e praças na mesma proporção. É preciso considerar também que alguns espaços livres não cumprem a sua função social, como é o caso das 48 praças não-urbanizadas do município, mas que aqui foram computadas.

Um novo estudo, que separe as áreas onde o lazer e a recreação podem acontecer de forma pública (como é o caso das praças consideradas pela PMU como urbanizadas) daquelas em que a visitação não pode ocorrer (ou porque a praça é "nãourbanizada" ou o parque se encontra fechado por falta de infra-estrutura e pessoal), apresentará um índice mais alarmante para a cidade de Uberlândia, além de servir como instrumento de reivindicação para a criação de novas áreas verdes públicas.

Houve a constatação, em alguns espaços livres visitados, da falta de infraestrutura e em alguns casos de pessoas incapacitadas para atender a função social dos parques e praças, ou seja, que envolvam o lazer, a recreação e a educação dos frequentadores. Em nenhum parque existe o real Plano de Manejo, documento de vital importância na garantia da conservação da diversidade biológica e dos ecossistemas dessas áreas. Nos parques onde a visitação pública é permitida, há a necessidade de alguns projetos voltados para a informação do público.

Desta forma, foi possível observar que a distribuição das áreas verdes não segue a densidade populacional e diminui a eficiência dessas áreas para os fins propostos, pois a distribuição de espaços livres no tecido urbano depende das características físicas do sítio, da existência de áreas históricas, do uso da terra e da estrutura urbana, como também da distribuição da população residente no espaço 
urbano e de suas características (espaços recreacionais), além, é claro, das estratégias de planejamento e intervenção, exigidos pelas diferentes leis, nos três níveis de poder.

\section{CONCLUSÕES}

Sendo o ambiente urbano heterogêneo, além da análise da distribuição populacional segundo sua densidade, recomenda-se considerar as necessidades e desejo da população de acordo com a composição etária, nível sócial e econômico, hábitos e costumes. Os espaços livres para recreação devem ser planejados segundo a análise da distribuição espacial da população atual e futura (estimativa), daí o alcance do objetivo das tabelas populacionais por setores e época.

Ainda sobre a distribuição espacial dos parques na cidade de Uberlândia que não recebem visitantes, voltados para a preservação, é necessário destacar que o sistema de regras de áreas verdes não pode se limitar à aquisição e reserva de grandes áreas na periferia da cidade, sem ao menos o conhecimento da população, da composição de infra-estrutura, técnicos especializados, planos de manejo e tantos outros, pois as mesmas podem perder seu caráter funcional.

De uma forma geral as condições ambientais segundo o índice encontrado é de desejável alerta, tanto nos aspectos quantitativos (objetivo dessa análise), quanto nos conseqüentes qualitativos, necessários de serem estudados e aprofundados em projetos futuros. Desta maneira, este estudo teve o objetivo de apresentar os procedimentos para o estabelecimento de um índice de áreas verdes por habitantes no perímetro urbano de Uberlândia, pois a divulgação do índice é o instrumento para reivindicação.

Além de efetivamente planejar novas áreas de praças e parques, os governos atuais devem planejar medidas que permitam diminuir as áreas impermeáveis e construídas em benefício de novas áreas permeáveis. Por exemplo, trocar alamedas asfaltadas por novas trilhas de terra e com plantio de espécies nativas (principalmente as plantas mais resistentes ao ambiente urbano), edificações antigas que não se prestarem mais às finalidades atuais e não sejam consideradas como patrimônio histórico, devem ser avaliadas para demolição e sua área tornada permeável novamente. São princípios de longo prazo, mas que promoverão qualidade ao índice de área verde com mais verde de fato, em direção à renaturalização.

O planejamento da distribuição de áreas verdes no ambiente urbano deve obedecer aos critérios de acessibilidade e das funções sociais e ecológicas, permitindo o contato direto do morador com os elementos do meio físico ao ressaltar a importância da conservação e da preservação para a qualidade ambiental urbana e, por fim, para a 
qualidade de vida, como sempre ensinou e defendeu o saudoso professor Felisberto Cavalheiro em suas aulas no Departamento de Geografia da FFLCH-USP.

\section{REFERÊNCIAS BIBLIOGRÁFICAS}

BARBIN, H. S. Histórico da evolução do uso do solo e estudo dos espaços livres públicos de uma região do município de Piracicaba/SP. Piracicaba, 2003. $214 \mathrm{f}$. Tese (Doutorado em Agronomia) - ESALQ/USP.

BRASIL. Constituição (1988). Constituição da República Federativa do Brasil. Brasília, DF: $1988 . \quad$ Denado, Disponível em: <http://www.senado.gov.br/sf/legislacao/const/con1988/CON1988_05.10.1988/CON198 8.pdf>. Acesso em: 17 novembro 2006.

BRASIL. Lei $\mathrm{n}^{0}$ 4.771, de 15 de Setembro de 1965. Código Florestal Brasileiro. Disponível em: <http://www.planalto.gov.br/ccivil 03/LEIS/L4771.htm>. Acesso em: 17 novembro 2006.

BRASIL. Lei $\mathrm{n}^{\circ}$ 84.017, de 21 de Setembro de 1979. Aprova o Regulamento dos Parques Nacionais Brasileiros. Disponível em: <http://www.lei.adv.br/84017-79.htm>. Acesso em: 17 novembro 2006.

BRASIL. Lei $n^{\circ} 6.766$, de 19 de Dezembro de 1979. Dispõe sobre o parcelamento do solo urbano. Disponível em: <http://www.planalto.gov.br/ccivil 03/leis/L6766.htm>. Acesso em: 17 novembro 2006.

BRASIL. Lei $n^{0} 9.785$, de 29 de Janeiro de 1999. Altera a Lei de uso e parcelamento do solo. Disponível em: <http://www.planalto.gov.br/ccivil 03/leis/L9785.htm>. Acesso em: 17 novembro 2006.

BRASIL. Lei $n^{0}$ 9.985, de 18 de Julho de 2000. Sistema Nacional de Unidades de Conservação da Natureza (SNUC). Disponível em: <http://www.planalto.gov.br/ccivil 03/LEIS/L9985.htm>. Acesso em: 17 novembro 2006. BRASIL. Lei $n^{0}$ 10.257, de 10 de Julho de 2001. Estatuto da Cidade. Disponível em: <http://www.planalto.gov.br/ccivil 03/LEIS/LEIS 2001/L10257.htm>. Acesso em: 17 novembro 2006.

BRITO, J. L. S.; PRUDENTE, T. Mapeamento do uso da terra e cobertura vegetal do município de Uberlândia - MG, utilizando as imagens CCD/CBERS 2. Caminhos de Geografia, 13(15), Uberlândia, p. 144-153, jun/2005.

CAVALHEIRO, F.; DEL PICCHIA, P. C. D. Áreas verdes: conceitos, objetivos e diretrizes para o planejamento. In: CONGRESSO BRASILEIRO DE ARBORIZAÇÃO URBANA, 1992, Vitória. Anais I e II. Vitória: CBAU, 1992. p. 29-35. 
CAVALHEIRO, F.; NUCCI, J. C. Espaços livres e qualidade de vida urbana. Paisagem Ambiente Ensaios n ${ }^{0} 11$, p. 277-288, 1998.

COSTA, R. G. S.; FERREIRA, C. C. M. Análise do índice de áreas verdes (IAV) na área central da cidade de Juiz de Fora, MG. Revista da Sociedade Brasileira de Arborização Urbana, v. 4, n. 1, Piracicaba, p. 39-57, mar/2009.

ESCADA. M. I. S. Caracterização dos espaços livres de uso público de São José dos Campos. Rio Claro, 1987. 45 f. Monografia (Bacharel em Ecologia) - UNESP.

GUZZO, P. Estudo dos espaços livres de uso público da cidade de Ribeirão Preto com detalhamento da cobertura vegetal e áreas verdes públicas de dois setores urbanos. Rio Claro, 1999. 125 f. Dissertação (Mestrado em Geociências) - Instituto de Biociências/UNESP.

INSTITUTO BRASILEIRO DE GEOGRAFIA E ESTATÍSTICA - IBGE. cidades@. Disponível em: <http://www.ibge.gov.br/cidadesat/topwindow.htm?1>. Acesso em: 18 novembro 2006.

LIMA, S. T. Verde urbano: uma questão de qualidade ambiental. In: ENCONTRO NACIONAL DE ESTUDOS SOBRE O MEIO AMBIENTE $n^{\circ} 3$, 1991, Londrina. Anais. Londrina: UEL, 1991. p. 27-39.

MAGALHÃES JR., A. P. Indicadores ambientais e recursos hídricos: realidade e perspectivas para o Brasil a partir da experiência francesa. Rio de Janeiro: Bertrand Brasil, 2007. $686 \mathrm{p}$.

MINAS GERAIS. Decreto $\mathrm{n}^{\circ} 21.724$, de 23 de Novembro de 1981. Aprova o Regulamento dos Parques Estaduais. Disponível em: <http://www.siam.mg.gov.br/sla/download.pdf?idNorma=1107>. Acesso em: 17 novembro 2006.

NUCCI, J. C. Qualidade ambiental \& adensamento urbano: um estudo de ecologia e planejamento da paisagem aplicado ao distrito de Santa Cecília (MSP). São Paulo: Humanitas/FFLCH/USP, 2001. 235 p.

OLIVEIRA, C. H. Planejamento ambiental na cidade de São Carlos/SP com ênfase nas áreas públicas e áreas verdes: diagnóstico e propostas. São Carlos, 1996. 181 f. Dissertação (Mestrado em Ecologia) - UFSCar.

PREFEITURA MUNICIPAL DE UBERLÂNDIA - PMU. Banco de dados integrados. Uberlândia: SEPLAMA, 105 p., vol. I, 2006. Disponível em: $<$ http://www.uberlandia.mg.gov.br/documentos/planejamento urbano e meio amb/BDI 2006 vol 1 RED.pdf>. Acesso em: 21 março 2007.

TOLEDO, F. S.; SANTOS, Douglas G. Espaços livres de construção. Revista da Sociedade Brasileira de Arborização Urbana, v. 3, n. 1, Piracicaba, p. 73-91, mar/2008. 
RONDINO, E. Áreas verdes como redestinação de áreas degradadas pela mineração: estudo de casos nos municípios de Ribeirão Preto, Itu e Campinas, Estado de São Paulo. Piracicaba, 2005. 126 f. Dissertação (Mestrado em Agronomia) ESALQ/USP.

SOARES, B. R.; BESSA, K. C. F. O.; OLIVEIRA, B. S.; ENGEL, A. S. Dinâmica urbana na bacia do Rio Araguari (MG) - 1970-2000. In: LIMA, S. C.; SANTOS, R. J. (orgs.) Gestão ambiental na bacia do Rio Araguari - rumo ao desenvolvimento sustentável. Uberlândia: UFU: IG; Brasília: CNPq, 221 p., 2004.

SOCIEDADE BRASILEIRA DE ARBORIZAÇÃO URBANA - SBAU. Carta a Londrina e Ibiporã. Boletim Informativo, v. 3, n. 5, 1996. p. 3.

UBERLÂNDIA. Lei complementar $n^{\circ}$ 017, de 04 de Dezembro de 1991. Dispõe sobre a política de proteção, controle e conservação do meio ambiente. Disponível em: <http://www.uberlandia.mg.gov.br/home legislacao.php?id=668>. Acesso em: 21 março 2007.

UBERLÂNDIA. Decreto $n^{0}$ 7.383, de 04 de Setembro de 1997. Regulamenta o projeto "adote uma praça ou um canteiro central". Disponível em: $<$ http://www.uberlandia.mg.gov.br/midia/documentos/meio ambiente/decreto 7383.pdf> . Acesso em: 04 abril 2007.

UBERLÂNDIA. Lei complementar $n^{\circ} 245$, de 30 de Novembro de 2000. Parcelamento e zoneamento do uso e ocupação do solo do município de Uberlândia. Disponível em: <http://www.uberlandia.mg.gov.br/home legislacao.php?id=655>. Acesso em: 17 março 2007.

UBERLÂNDIA. Lei Orgânica do Município de Uberlândia, 8a edição, 2006. Disponível em: <http://www.uberlandia.mg.gov.br/home legislacao.php?id=773>. Acesso em: 21 novembro 2006.

UBERLÂNDIA. Lei complementar $n^{\circ} 432$, de 19 de Outubro de 2006. Aprova o Plano Diretor do município de Uberlândia, estabelece os princípios básicos e as diretrizes para sua implantação, revoga a Lei Complementar $n^{\circ} 078$ de 27 de Abril de $1994 . \quad$ Disponível em: $<$ http://www3.uberlandia.mg.gov.br/midia/documentos/planejamento urbano/leic 432.pd f>. Acesso em: 17 março 2007. 